\title{
PET/CT without capacity limitations: a Danish experience from a European perspective
}

\author{
Poul Flemming Høilund-Carlsen • Oke Gerke • Mie Holm Vilstrup • \\ Anne Lerberg Nielsen • Anders Thomassen • Søren Hess • Mette Høilund-Carlsen • \\ Werner Vach $\cdot$ Henrik Petersen
}

Received: 24 July 2010 /Revised: 7 October 2010 /Accepted: 12 October 2010 /Published online: 28 January 2011

(C) The Author(s) 2011. This article is published with open access at Springerlink.com

\begin{abstract}
Objectives We report the 3-year clinical experience of a large new Danish PET/CT centre without capacity limitations in relation to national and European developments. Methods The use of PET/CT in cancer was registered from early 2006 to early 2009 to judge the impact on patient management and to compare it with national and European trends.

Results 6056 PET/CT examinations were performed in 4327 patients. Activity increased by 86 examinations per month compared with the same month the year before. Referrals came primarily from oncology $(23.0 \%)$, haematology (21.6\%), surgery (12.6\%), internal medicine (12.7\%) and gynaecology $(5.5 \%)$. Referral indications were diagnosis $(31.3 \%)$, staging $(22.3 \%)$, recurrence detection $(21.2 \%)$, response evaluation $(17.0 \%)$ and other $(8.2 \%)$. Response from nearly $60 \%$ of users showed that PET/CT caused a change in diagnosis and/or staging and/or treatment plan in $36.0 \%$ of cases. During the study period, there was a steep increase in the national use of FDG and in the European use of PET/CT.

Conclusions We recorded a constantly increasing use of $\mathrm{PET} / \mathrm{CT}$ that caused a change in diagnosis and/or staging
\end{abstract}

P. F. Høilund-Carlsen $(\bowtie) \cdot$ O. Gerke $\cdot$ M. H. Vilstrup •

A. L. Nielsen · A. Thomassen - S. Hess • M. Høilund-Carlsen •

H. Petersen

Department of Nuclear Medicine, PET \& Cyclotron Unit,

Odense University Hospital,

Sdr. Boulevard 29,

DK-5000, Odense C, Denmark

e-mail: pfhc@ouh.regionsyddanmark.dk

W. Vach

Clinical Epidemiology Group, Institute of Biometry and Medical Informatics, University Medical Center Freiburg,

Freiburg, Germany and/or treatment plan in $36.0 \%$ of cases. In line with national and European trends this may suggest a shift in favour of functional rather than anatomical imaging.

Keywords Radionuclide imaging $\cdot \mathrm{PET} / \mathrm{CT} \cdot$ Referral pattern $\cdot$ Indications $\cdot$ Clinical impact

\section{Introduction}

The combination positron emission tomography/computed tomography (PET/CT) has changed nuclear medicine and focused on the diversities of functional and anatomical imaging and the advantages of combined imaging with image fusion. By 2005, stand-alone PET systems were no longer produced. In 2005, the US Centers of Medicare and Medicaid Services decided to give coverage to FDG PET in several cancers with the clause that its use be registered in a "National Oncologic PET Registry" [1, 2]. With the growing use of PET/CT worldwide and the advent of new tracers for more specific imaging procedures guidance has been given on both sides of the Atlantic [3-5] and a debate on how to monitor cancer therapy by functional rather than anatomical imaging is developing [6-8].

In the Nordic countries, the first PET facilities were established in Stockholm and Uppsala (in the late 1970searly 1980s) followed by Turku (1988), Copenhagen (1989) and Aarhus (1993), mainly focusing on brain research except for a broader profile in Turku which became a national research institution in 1996 [9-11]. In Denmark, clinical application lagged behind until 4 years ago, when politicians suddenly realised that cancer management in this country was slow, insufficient and for some cancers blemished by unacceptably poor survival rates. Consequently, the Danish government announced that 
cancer should be treated as an acute disease. To prevent bottlenecks in the public healthcare system providing more than $98 \%$ of hospital services, the five Danish regions decided in 2007 on a "National Danish Invitation to Tender for the Deliver of Cancer Scanners" which doubled the Danish stock of PET/CT systems. Alongside this, the Danish National Board of Health decided to establish National Integrated Pathways for cancer management, 34 of which were finished in 2009. Against this background, we report our experiences from the first 3 years of existence of a new and large PET centre in Odense, Denmark, and compare these activities with available data from the Danish Institute of Radiation Protection [12] and from the European Association of Nuclear Medicine (EANM) [13-15].

\section{Materials and methods}

Denmark has approximately 5.5 million inhabitants spread over a peninsula (Jutland with Aarhus as the main town), two major islands (Funen with Odense and Zealand with the capital Copenhagen) and several smaller islands. It comprises five administrative regions: Capital, Zealand, Southern, Central and North. Our Department of Nuclear Medicine is situated in Odense in the middle of Funen with its 500,000 inhabitants. Odense University Hospital (OUH) is the largest hospital on Funen and in the Region of Southern Denmark (1.2 million inhabitants) and represents together with Svendborg Hospital in Southern Funen the largest administrative hospital unit in Denmark.

OUH is part of the University of Southern Denmark, the third largest university in Denmark, and is home to one of five major cancer centres in Denmark. Against this background it was decided to build a new PET centre with cyclotron and radiochemical facilities, and on 28 February 2006 the first patient was examined by PET/CT. During the first year, all examinations were performed with a single PET/CT (General Electronic Discovery STE PET/CT with a Continuum VCT 16 slice CT) using exclusively 2-deoxy-2[18F]-fluoro D-glucose (FDG) produced at the cyclotrons at Rigshospitalet in Copenhagen or at Risø DTU National Laboratory in Roskilde, until permission for local production in Odense was granted by the Danish Medicines Agency. In early 2007, two additional PET/CT systems were added (General Electric Discovery VCT 64 slice CT and Discovery Rx 64 slice CT). From the second year on, FDG was produced in Odense and a few other tracers ([18F]DOPA, [18F]choline, and [18F]fluoride) were gradually introduced into clinical practice. All patients fasted $6 \mathrm{~h}$ before examination and rested approximately $1 \mathrm{~h}$ after the intravenous injection of tracer. All underwent wholebody or partial-body imaging from the base of the skull to mid-thigh. All patients who could tolerate a contrast agent received this intravenously and orally, and all patients with known or suspected malignancies allowing measurement of tumour size had a diagnostic $\mathrm{CT}$ at least on their first visit. Dual time PET, i.e., early and late acquisition was not applied. The reports were generated jointly by a nuclear medicine physician and a radiological specialist.

Data from all examinations were collected consecutively and prospectively on pre-defined case report forms comprising questions regarding working diagnosis, purpose of the PET/CT investigation (diagnosis, staging, recurrence detection, response assessment, etc.), and the imaging process (before, during and after). Feedback from the referring clinical departments or practitioners was collected to evaluate if the PET/CT did confirm and/or lead to changes in the working diagnosis, staging and/or the treatment plan. This was done by sending the referring departments a special form together with the PET/CT report. If the form was not returned, departments were requested to answer twice within a half year. If this was unsuccessful, the answer was considered lost. Statistical analyses were basically of descriptive nature. Exploratory Cochran-Armitage trend tests were performed at a significance level of 5\% (two-sided testing) without adjustment for multiplicity. All analyses were done in SASC , version 9.1.3.

Available data for comparison were collected from the Danish Institute of Radiation Protection in the shape of the recorded yearly use of FDG and other PET radiopharmaceuticals [12], as well as from the EANM, which from the years 2006, 2007 and 2009 (no data from 2008) retrieved data on the use of PET and PET/CT from an increasing number of European member societies, including the number of various types of systems and imaging made by each technique [13-15].

\section{Results}

Imaging

A total of $6056 \mathrm{PET} / \mathrm{CT}$ were performed in 4327 patients, $3459(79.9 \%)$ of whom had only one scan, whereas 868 (20.1\%) had two or more examinations, for details see Table 1 which displays the number of examinations in relation to the working diagnosis according to level 2 of the International Classification of Diseases, version 10 (ICD10) [16]. In almost half of patients with three or more PET/ CT, the working diagnosis was "Neoplasms of lymphoid, haematopoietic and related tissue", whereas the working diagnoses of the remaining patients were distributed in small portions. The number of investigations peaked in January, February and October, each with approximately 


\begin{tabular}{|c|c|c|c|c|c|c|c|c|}
\hline 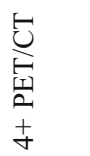 & 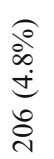 & 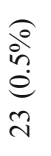 & $\begin{array}{l}\stackrel{0}{\circ} \\
\stackrel{i}{e} \\
\stackrel{1}{c}\end{array}$ & 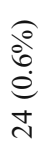 & $\frac{\hat{\partial}}{e}$ & $\begin{array}{l}\hat{\circ} \\
\text { iे } \\
\stackrel{0}{0} \\
0\end{array}$ & $\begin{array}{l}\text { o̊ } \\
\text { ì } \\
d \\
0\end{array}$ & $\begin{array}{l}\frac{0}{0} \\
i n \\
0 \\
\dot{e} \\
\sim\end{array}$ \\
\hline $\begin{array}{l}-v \\
巳 \\
\frac{1}{2} \\
m \\
m\end{array}$ & 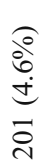 & 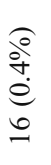 & $\begin{array}{l}\text { oे } \\
\text { iे } \\
e \\
\pm \\
\pm\end{array}$ & $\begin{array}{l}\text { o } \\
\dot{b} \\
\stackrel{0}{0} \\
\dot{d}\end{array}$ & $\begin{array}{l}\hat{\circ} \\
\stackrel{0}{0} \\
\stackrel{0}{e} \\
m\end{array}$ & $\begin{array}{l}\hat{\circ} \\
\text { iे } \\
e \\
n \\
n\end{array}$ & $\begin{array}{l}\stackrel{2}{2} \\
\stackrel{\text { d }}{d} \\
a\end{array}$ & $\begin{array}{l}\hat{0} \\
\stackrel{0}{0} \\
\stackrel{0}{e}\end{array}$ \\
\hline 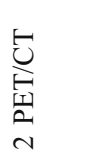 & $\begin{array}{l}\stackrel{0}{\stackrel{2}{2}} \\
\stackrel{0}{0} \\
\stackrel{0}{0}\end{array}$ & 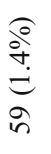 & $\begin{array}{l}\stackrel{0}{\circ} \\
\stackrel{\infty}{\oplus} \\
\stackrel{2}{2}\end{array}$ & 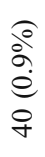 & 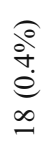 & $\begin{array}{l}\text { oे } \\
\infty \\
0 \\
e \\
\dot{e}\end{array}$ & 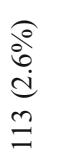 & $\begin{array}{l}\text { ò } \\
\text { in } \\
e \\
\text { cं }\end{array}$ \\
\hline 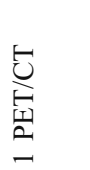 & 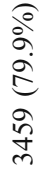 & $\begin{array}{l}o \\
i n \\
\infty \\
a \\
0 \\
0\end{array}$ & 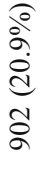 & 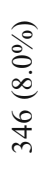 & 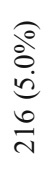 & $\begin{array}{l}\frac{0}{0} \\
\frac{a}{a} \\
\frac{n}{n}\end{array}$ & $\begin{array}{l}\stackrel{0}{\stackrel{0}{0}} \\
\stackrel{n}{=} \\
=\end{array}$ & 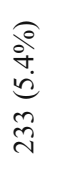 \\
\hline 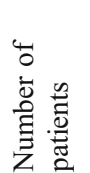 & 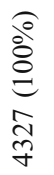 & 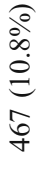 & $\begin{array}{l}\text { oे } \\
\text { iे } \\
\text { 己े } \\
\hat{8}\end{array}$ & 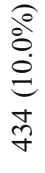 & 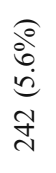 & 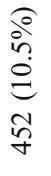 & 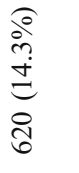 & 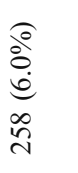 \\
\hline 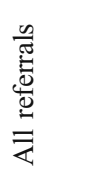 & 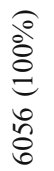 & 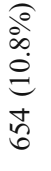 & $\begin{array}{l}\stackrel{0}{\circ} \\
\stackrel{\infty}{=} \\
\text { 吉 } \\
=\end{array}$ & 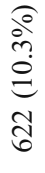 & 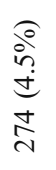 & 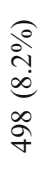 & 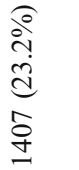 & 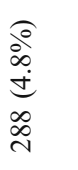 \\
\hline$\stackrel{e}{\Xi}$ & & 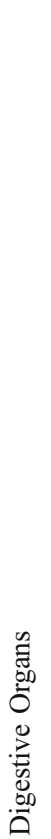 & 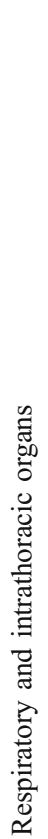 & 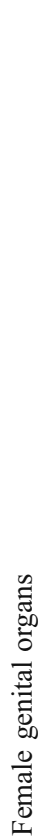 & 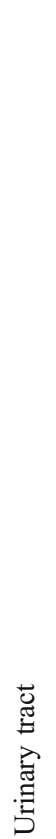 & 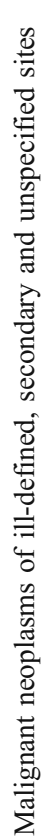 & 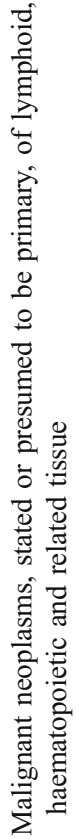 & 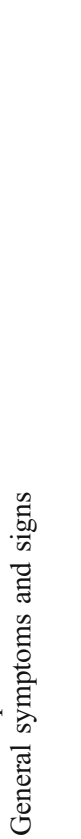 \\
\hline ํㅛ & 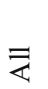 & & & 8 & & & $\frac{1}{\infty} \stackrel{\circ}{0}$ & 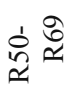 \\
\hline
\end{tabular}

$10 \%-11 \%$ of the yearly production, whereas March $(6 \%)$, April (6.6\%) and July (6.5\%) were the least busy months.

Patient disposition

There were 2113 (48.8\%) female and 2214 (51.2\%) male patients, and 35 patients $(0.8 \%), 7$ girls and 28 boys, below an age of 18 years (range $1-17$ ). The mean age (5th and 95 th percentiles) of female and male patients was 62.6 years (36 to 83 years) and 63.5 years (35 to 82 years), respectively. Body mass index $\left(\mathrm{kg} \cdot \mathrm{m}^{-2}\right)$ was $24.7(18.0$ to 34.6$)$ in female and 25.5 (19.3 to 32.9) in male patients. All examined patients were referred with known or suspected cancer. The frequencies of reported comorbidities were as follows: allergy $17.5 \%$, diabetes $9.1 \%$, cardiac disease $15.4 \%$, arterial hypertension $29.7 \%$, hypercholesterolaemia $17.1 \%$ and reduced kidney function $6.3 \%$ (multiple indications in single patients possible). Moreover, $30.9 \%$ of patients had undergone an operation within the last 2 months before imaging, 1.0\% had undergone radiation therapy and $1.2 \%$ chemotherapy.

\section{Referrals}

Most referrals (4965 out of 6056 , or $82.0 \%$ ) were received from OUH, 492 (8.1\%) from other Funen hospitals, 510 $(8.4 \%)$ from other hospitals in the Region of Southern Demark and $21(0.3 \%)$ from hospitals in other regions of Demark. Additionally, $47(0.8 \%)$ came from General Practitioners, and $7(0.1 \%)$ from practicing specialists in the region. About $75 \%$ of referrals came from oncology (23.0\%), haematology $(21.6 \%)$, surgery $(12.6 \%)$, internal medicine $(12.7 \%)$ and gynaecology $(5.5 \%)$.

Indications

Classifying according to level 1 of the ICD-10, 5571 (92.0\%) and 291 (4.8\%) patients had working diagnoses belonging to the classes "Neoplasms" (C00-D48) and "Symptoms, signs and abnormal clinical and laboratory findings, not elsewhere classified" (R00-R99), respectively.

Refining the classification of diseases to a lower level indicated that $10.8 \%$ had known or suspected malignancies in the digestive organs (C15-C26), 18.9\% in the respiratory and intrathoracic organs (C30-C39), 10.2\% in the female genital organs (C51-C58), whereas 8.1\% were classified as having neoplasms of ill-defined, secondary and unspecified sites (C76-C80), and 23.1\% cancer of lymphoid, haematopoietic and related tissue (C81-C96) (see Table 2). Most patients were referred for PET/CT with a known disease $(N=4397(72.6 \%))$, whereas approximately every fourth patient was referred with an expectation about disease $(N=1602$ (26.4\%)). Most 
Table 2 Working diagnosis of referred patients according to the International Classification of Diseases, version 10 (ICD-10) [16]

\begin{tabular}{|c|c|c|c|c|c|}
\hline ICD Code & Title & All referrals & Known disease & Expected disease & Missing \\
\hline All & & $6056(100 \%)$ & $4397(72.6 \%)$ & $1602(26.5 \%)$ & $57(0.9 \%)$ \\
\hline $\mathrm{C} 00-\mathrm{C} 14$ & Lip, oral cavity and pharynx & $90(1.5 \%)$ & $78(1.3 \%)$ & $11(0.2 \%)$ & $1(0.02 \%$ \\
\hline $\mathrm{C} 15-\mathrm{C} 26$ & Digestive Organs & $654(10.8 \%)$ & $604(10.0 \%)$ & $46(0.8 \%)$ & $4(0.07 \%$ \\
\hline C30-C39 & Respiratory and intrathoracic organs & $1147(18.9 \%)$ & $493(8.1 \%)$ & $649(10.7 \%)$ & $5(0.08 \%$ \\
\hline $\mathrm{C} 43-\mathrm{C} 44$ & Skin & $293(4.8 \%)$ & $284(4.7 \%)$ & $8(0.1 \%)$ & $1(0.02 \%$ \\
\hline $\mathrm{C} 50-\mathrm{C} 50$ & Breast & $229(3.8 \%)$ & $212(3.5 \%)$ & $14(0.2 \%)$ & $3(0.05 \%$ \\
\hline C51-C58 & Female genital organs & $622(10.3 \%)$ & $479(7.9 \%)$ & $139(2.3 \%)$ & $4(0.07 \%)$ \\
\hline C60-C63 & Male genital organs & $195(3.2 \%)$ & $191(3.2 \%)$ & $2(0.03 \%)$ & $2(0.03 \%)$ \\
\hline C64-C68 & Urinary tract & $274(4.5 \%)$ & $244(4.0 \%)$ & $25(0.4 \%)$ & $5(0.08 \%$ \\
\hline $\mathrm{C} 73-\mathrm{C} 75$ & Thyroid and other endocrine glands & $77(1.3 \%)$ & $61(1.0 \%)$ & $15(0.2 \%)$ & $1(0.02 \%$ \\
\hline $\mathrm{C} 76-\mathrm{C} 80$ & Malignant neoplasms of ill-defined, secondary and unspecified sites & $498(8.2 \%)$ & $190(3.1 \%)$ & $303(5.0 \%)$ & $5(0.08 \%$ \\
\hline C81-C96 & $\begin{array}{l}\text { Malignant neoplasms, stated or presumed to be primary, of lymphoid, } \\
\text { haematopoietic and related tissue }\end{array}$ & $1407(23.2 \%)$ & $1288(21.3 \%)$ & $108(1.8 \%)$ & $11(0.2 \%)$ \\
\hline R50-R69 & General symptoms and signs & $288(4.8 \%)$ & $148(2.4 \%)$ & $135(2.2 \%)$ & $5(0.08 \%$ \\
\hline Z00-Z13 & Persons encountering health services for examination and investigation & $79(1.3 \%)$ & $6(0.1 \%)$ & $73(1.2 \%)$ & $0(0 \%)$ \\
\hline
\end{tabular}

patients with known disease belonged to the classes digestive organs $(10.0 \%)$, respiratory and intrathoracic organs $(8.1 \%)$ and neoplasms of lymphoid, haematopoietic and related tissue $(21.3 \%)$, whereas codes of cancer in respiratory and intrathoracic organs (10.7\%), female genital organs $(2.3 \%)$, and neoplasms of ill-defined, secondary and unspecified sites $(5.0 \%)$ were most pronounced in patients with expected disease.

The purpose of referring the patient for PET/CT was diagnosis alone in $31.3 \%$ of patients, staging alone in $22.3 \%$, recurrence detection alone in $21.2 \%$, or response assessment alone in $17.0 \%$, whereas combinations of these or target definition, follow-up, or research appeared to be the reason for the remaining $8.2 \%$. Diagnosis was the main purpose in lung cancer, cancer of unknown primary, and patients presenting with "General symptoms and signs" (see Table 3). Staging was the main purpose in patients with malignant lymphomas and lung cancer, whereas detection of recurrence was the main purpose in patients with cancer in digestive organs and neoplasms of lymphoid, haematopoietic and related tissue. Response evaluation was the main reason for imaging in patients with neoplasms of lymphoid, haematopoietic and related tissue.

Tracers, systems, procedures

FDG was by far the most commonly used tracer $(N=$ $5933(98.0 \%))$, whereas other tracers were produced and used on occasion ([18F]choline: $N=82(1.4 \%),[18 \mathrm{~F}]$ DOPA: $N=25(0.4 \%)$, [18F]fluoride: $N=11(0.2 \%))$. System no. 1 was used most $(N=3349(55.3 \%))$ followed by systems no. $2(N=1653(27.3 \%))$ and no. $3(N=1028$ $(17.0 \%))$. Diagnostic CT was more frequently used $(N=$ $3613(59.7 \%)$ ) than low-dose CT. Oral contrast medium was also used in most cases $(N=3521(58.1 \%))$. Intravenous contrast medium was used in more than every second

Table 3 Reasons for referral to PET/CT in relation to working diagnosis

\begin{tabular}{|c|c|c|c|c|c|c|c|}
\hline ICD Code & Title & All referrals & Diagnosis & Staging & Recurrence & Response & $\begin{array}{l}\text { Combinations } \\
\text { or other }\end{array}$ \\
\hline All & & $6056(100 \%)$ & $1898(31.3 \%)$ & $1349(22.3 \%)$ & $1281(21.2 \%)$ & $1028(17.0 \%)$ & $500(8.2 \%)$ \\
\hline $\mathrm{C} 15-\mathrm{C} 26$ & Digestive Organs & $654(10.8 \%)$ & $48(0.8 \%)$ & $165(2.7 \%)$ & $271(4.5 \%)$ & $89(1.5 \%)$ & $81(1.3 \%)$ \\
\hline C30-C39 & Respiratory and intrathoracic organs & $1147(18.9 \%)$ & $630(10.4 \%)$ & $269(4.4 \%)$ & $173(2.9 \%)$ & $32(0.5 \%)$ & $43(0.7 \%)$ \\
\hline C51-C58 & Female genital organs & $622(10.3 \%)$ & $132(2.2 \%)$ & $179(3.0 \%)$ & $181(3.0 \%)$ & $87(1.4 \%)$ & $43(0.7 \%)$ \\
\hline C64-C68 & Urinary tract & $274(4.5 \%)$ & $24(0.4 \%)$ & $182(3.0 \%)$ & $47(0.8 \%)$ & $10(0.2 \%)$ & $11(0.2 \%)$ \\
\hline $\mathrm{C} 76-\mathrm{C} 80$ & $\begin{array}{l}\text { Malignant neoplasms of ill-defined, } \\
\text { secondary and unspecified sites }\end{array}$ & $498(8.2 \%)$ & $438(7.2 \%)$ & $9(0.1 \%)$ & $16(0.3 \%)$ & $19(0.3 \%)$ & $16(0.3 \%)$ \\
\hline C81-C96 & $\begin{array}{l}\text { Malignant neoplasms, stated or } \\
\text { presumed to be primary, of } \\
\text { lymphoid, haematopoietic } \\
\text { and related tissue }\end{array}$ & $1407(23.2 \%)$ & $108(1.8 \%)$ & $277(4.6 \%)$ & $231(3.8 \%)$ & $659(10.9 \%)$ & $132(2.2 \%)$ \\
\hline R50-R69 & General symptoms and signs & $288(4.8 \%)$ & $274(4.5 \%)$ & $0(0 \%)$ & $2(0.03 \%)$ & $1(0.02 \%)$ & $11(0.2 \%)$ \\
\hline
\end{tabular}


patient $(N=3246(53.6 \%))$. Actually, in 3172 patients (52.4\%) diagnostic $\mathrm{CT}$, oral contrast medium and intravenous contrast medium were used together, whereas diagnostic $\mathrm{CT}$ and oral contrast medium were only used in 326 patients $(5.4 \%)$ without intravenous contrast medium. In 3418 examinations (56.4\%), imaging fields 2 to 5 were used, whereas 1 to 5 were used 2323 times (38.4\%) and 1 to 7 were used 86 times (1.4\%).

The examination was performed without any discomfort 4961 times $(81.9 \%$ ), whereas minor problems (discomfort, anxiety, phobia, issues with needle insertion or injection of $\mathrm{x}$-ray contrast medium, technical problems with the hardware and/or software) were reported 512 times $(8.5 \%)$, while data were missing in the remaining $9.6 \%$. Side effects like nausea following administration of intravenous or oral contrast medium (with and without vomiting) or an allergic reaction at the puncture wound following administration of intravenous contrast medium were observed in only 20 examinations $(0.3 \%)$. The quality of the imaging was "fine" in 4719 cases (77.9\%), "acceptable" in 189 cases (3.1\%), and led to a repeat acquisition in only 8 cases $(0.1 \%)$, while data were missing in the remaining cases. The PET/CT report was considered "clear" by the referring physicians/departments in 3291 examinations (54.3\%) and unclear in 191 examinations $(3.2 \%)$, whereas $2574(42.5 \%)$ readings were not judged.

\section{Clinical impact}

Feedback on 3559 cases (58.8\%) was obtained from the referring departments. According to these responses, the PET/CT examination confirmed the working diagnosis in 1911 cases (53.7\%), the staging in 1518 (42.7\%) and the treatment plan in 1774 cases $(49.9 \%)$, respectively, and caused a change in diagnosis in $508(14.3 \%)$, staging in 788 (22.1\%) and treatment plan in 1007 cases (28.3\%) (Fig. 1). The result of PET/CT changed at least one of them (diagnosis and/or staging and/or treatment plan) in 36.0\% of cases. Diagnostic CT was used in $51.3 \%$ of these applying intravenous and oral contrast in $86.1 \%$.

\section{Trends}

With an increasing number of systems the number of examinations grew over time, i.e., from 971 in year 1 to 2020 and 3065 in year 2 and 3, respectively. The working diagnoses varied little except for a decrease in cancer in digestive organs from $15.8 \%$ in year 1 to $8.6 \%$ in year $3(p<$ 0.0001 ), in skin cancers from $6.4 \%$ in year 1 to $3.9 \%$ ( $p=$ 0.0003 ) and in neoplasms of ill-defined, secondary and unspecified sites from $10.4 \%$ to $7.8 \%(p=0.03)$, whereas there was an increase in "General symptoms and signs" from

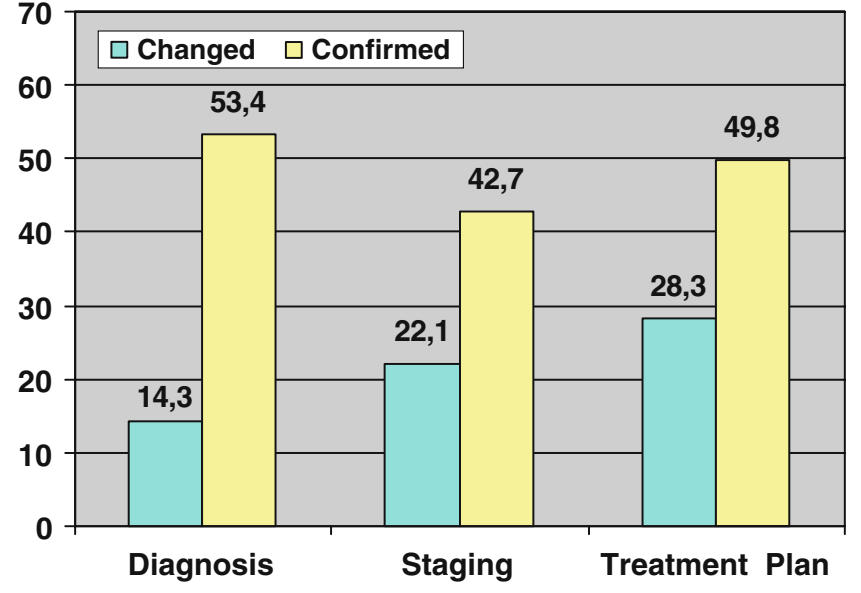

Fig. 1 Reported use of FDG PET/CT for diagnosis, staging, detection of recurrence and response evaluation. The y-axis displays the percentage of examinations

$0.7 \%$ in year 1 to $6.7 \%$ in year $3(p<0.0001)$. Regarding referrals, for only 3 referring departments at OUH did the rate of referrals differ over time: The outpatient clinics of Gynaecologic Oncology (from $0 \%$ in year 1 to $5.2 \%$ in year $3, p<0.0001$ ), Oncology (from $24.4 \%$ in year 1 to $20.5 \%$ in year 3, $p=0.04$ ), and Urology (from $0 \%$ in year 1 to $3.7 \%$ in year $3, p<0.0001$ )

There was a tendency for an increase in confirmation rate of PET/CT over time and, conversely, a tendency for decrease in the rate of change caused by PET/CT in diagnosis, staging and treatment (Table 4). The use of other tracers than FDG did not increase during this period. Diagnostic CT was more frequently used than low-dose CT during all 3 years and the use of oral contrast increased from $49.4 \%$ in year 1 to $59.2 \%$ in year 3 .

\section{Danish use of PET radiopharmaceuticals}

The use of FDG and other PET radiopharmaceuticals reflected a relatively low and fairly constant level of activity until 2004-2005 followed by a steep increase of approximately 55\% each year in 2006, 2007 and 2008, albeit with a limited use of tracers other than FDG (see Fig. 3) [15].

European tendencies

According to EANM, there was from 2006 to 2009 a decrease in the stock of PET systems, from 163 (in 26 countries) to 145 (in 35 countries) and an increase in PET/ CT systems from 166 (in 27 countries) to 463 (in 35 countries) $(+179 \%)$. Similarly, there was from 2007 to 2009 an increase in the number of PET+PET/CT from 352,872 to $597,874(+69 \%$ despite lacking data from Belgium and the Netherlands) [12-14]. 
Table 4 Trends for rate of confirmation and rate of change in diagnosis, staging and treatment plan over the 3 years

\begin{tabular}{|c|c|c|c|c|c|}
\hline & & Year 1 & Year 2 & Year 3 & Test for trend \\
\hline \multirow[t]{3}{*}{ Confirmation } & Diagnosis & $51.0 \%$ & $54.5 \%$ & $54.7 \%$ & $P=0.13$ \\
\hline & Staging & $37.6 \%$ & $45.6 \%$ & $42.5 \%$ & $P=0.06$ \\
\hline & Treatment plan & $45.3 \%$ & $51.8 \%$ & $50.6 \%$ & $P=0.03$ \\
\hline \multirow[t]{3}{*}{ Change } & Diagnosis & $16.3 \%$ & $13.4 \%$ & $13.9 \%$ & $P=0.16$ \\
\hline & Staging & $27.4 \%$ & $20.7 \%$ & $20.1 \%$ & $P<0.001$ \\
\hline & Treatment plan & $32.6 \%$ & $27.6 \%$ & $25.9 \%$ & $P=0.0012$ \\
\hline Change in at least one of them & Diagnosis and/or staging and/or treatment plan & $41.0 \%$ & $34.3 \%$ & $34.4 \%$ & $P<0.0001$ \\
\hline
\end{tabular}

\section{Discussion}

With fluctuations, the use of PET/CT in Odense increased linearly since the beginning with one system in early 2006 . With the addition of two systems in 2007 capacity limitations did not appear within the first 3 years. Instead, the number of examinations increased on average by 86 each month compared with the same month the year before (Fig. 2). Not surprisingly, oncology and haematology were the most common reasons for use of PET/CT followed by surgery (mainly breast and colorectal cancer), internal medicine (mainly lung cancer) and gynaecology (ovarian, cervical and uterine cancer). These specialties accounted for about $3 / 4$ of all referrals. Most PET/CT were made in patients with known disease, i.e. primarily haematological cancers and cancers in the digestive organs, the respiratory organs, the female genitals and the breasts, accounting for $21.3 \%, 10.0 \%, 8.1 \%, 7.9 \%$ and $3.5 \%$, respectively. Among patients with unknown disease, most had suspected cancer in the respiratory tract $(10.7 \%)$, ill-defined neoplasms $(5.0 \%)$ and cancer in the female genitals $(2.3 \%)$, followed by patients with general symptoms and signs (2.2\%) (Table 2). PET/CT for diagnosis was mainly applied early in lung cancer, while staging and recurrence detection was more evenly used among the most common cancers, whereas response evaluation was the purpose almost exclusively in malignant lymphomas with sporadic use also in gastro-intestinal and female genital cancer (Table 3).

With regard to clinical impact our survey was somewhat blemished by a relatively high percentage of missing answers $(41.3 \%)$. Moreover, the distinction between indications (diagnosis, diagnosis/staging, or staging alone) was not always clear cut, as consensus on definitions of terms could for practical reasons not be made beforehand, and also because the timing of PET/CT in the work-up varied from one type of cancer to another. Over the 3 years, we observed a slight increase in the proportion of patients who had confirmation of what was expected by the clinicians, whereas the proportion of benefit for PET/CT with regard to change in diagnosis, staging and treatment plan decreased from year 1 to a slightly lower, but similar, level in year 2 and 3 (Table 4). Overall, FDG PET/CT was found to change the working diagnosis, staging and treatment plan in $14.3 \%, 22.1 \%$ and $28.3 \%$ of cases, respectively, causing a change in at least one of them in $36.0 \%$ of the cases, which the referring departments were able to judge. They indicated that they could not do this in $10 \%-16 \%$ of cases and in another $3 \%-4 \%$ they did not provide an answer.
Fig. 2 The monthly development in PET/CT at Odense University Hospital. The y-axis displays the number of examinations. The dotted horizontal red line indicates the maximum practical capacity with three PET/CT systems according to the Danish National Board of Health [26]

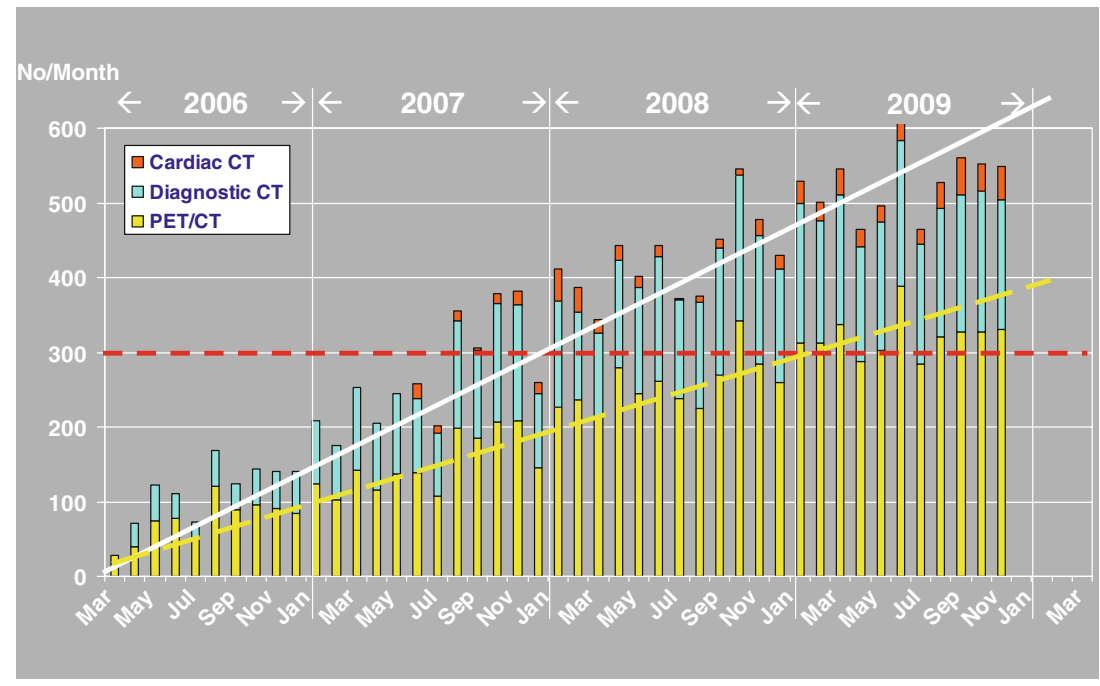


These kinds of figures were not given in previous singlecentre studies on early experience with PET without CT reporting $90 \%$ and $71 \%$ response rates in 517 and 743 cases $[17,18]$, respectively, or in a twin-centre study with a return rate of just $22 \%$ in 1500 cases [19]. Representing the experience of a community centre [17] and tertiary centres $[18,19]$ previous authors reported a change in management/therapy in $45 \%$ [17] and $43 \%$ [18], respectively, and a change in management in $39 \%$ and in therapy in $10 \%$ of cases [19]. In an American single-centre study of 248 out of an unknown number of cases, intended management was changed in $61 \%$ of patients [20]. The question of false positive rates with PET/CT and its ability to distinguish malignant from non-malignant abnormalities was not addressed in the previous studies or in our survey. The reason was for our part that follow-up with histopathological diagnosis and/or long term clinical outcome in all patients was beyond our practical possibilities.

Our study is the first to report the impact of PET/CT in a large consecutive series of patients. A similarly large survey from Australia observed that indications for PET/CT largely reflected Medicare reimbursement policy; however, this study did not record changes in patient handling after imaging [21]. As a whole, the cited studies vary to a degree, making proper comparison virtually impossible except that all studies reported substantial changes in management and/ or therapy albeit without definition and partition of these terms. Our finding of a change in diagnosis/staging or treatment plan in $36.0 \%$ of cases corresponds with the initial results of the National Oncologic PET Registry in the USA based on data from 22,975 studies $(83.7 \%$ PET/CT) according to which physicians changed their intended management in $36.5 \%$ of cases after PET [22]. Focusing on therapy alone, our referring physicians reported a change in treatment plan in $28.3 \%$ cases compared with a switch in physician-intended treatment after about $26.5 \%$ of imaging procedures in the PET Registry cases [23]. Although highly relevant, the degree PET/CT could displace other imaging was not covered in our or any of the previous surveys. An indication appears in a large health technology assessment from the UK, which concluded that PET/CT did in general improve accuracy by $10-15 \%$ over PET in six cancers and that PET/CT has higher sensitivity and accuracy than CT/ MRI in a variety of cancers [24]. Accordingly, in the PET Registry article on the impact on management, after $90 \%$ of imaging procedures, referring physicians indicated that the imaging results allowed them to avoid other imaging or invasive procedures [23].

The very pronounced increase in number of PET/CT examinations that we observed during all 3 years was accompanied by only minor changes in how PET/CT was used. We did not manage to introduce to a noticeable degree any of the many promising new tracers that are constantly reported in the literature. Surprisingly, this tendency was a national one for the same years (Fig. 3). Thus, apparently the two oldest medical cyclotron and radiochemical facilities in Denmark (in Aarhus and Copenhagen) did not change their production profile during these 3 years while two more recent ones, established 2006-7 in Odense and at Risø National Research Centre in Roskilde, were too new to manage the introduction of new radiopharmaceuticals during the period in question. In Odense, the use of non-FDG tracers increased only from $2(0.03 \%)$ in 2006 to $82(2.7 \%)$ in 2008. Nationwide, this may reflect that the introduction of new PET tracers is a timeconsuming and costly affair, not to mention difficulty in obtaining permission from the Medicines Agencies which consider radiopharmaceuticals on a par with drugs in general, a notion that may seriously threaten the future of molecular imaging [25]. From being behind at the start of the millennium, a growing political focus on cancer doubled the country's stock of PET/CT systems within 3 years. However, even with this high density of equipment the yearly need in $2008-10$ of 38,000 PET estimated by the
Fig. 3 The development of PET and PET/CT examinations in Denmark with FDG and tracers other than FDG [16]. Since 2005 the average annual increase in FDG PET and FDG $\mathrm{PET} / \mathrm{CT}$ has been $55 \%$

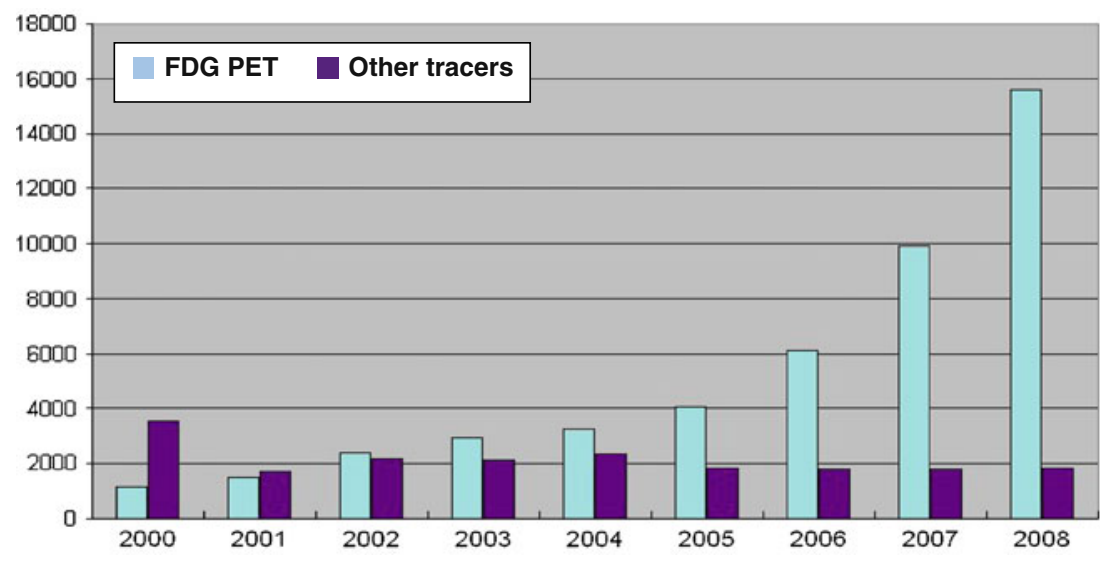


Danish Board of Health in 2006 cannot be met unless the equipment is utilised more efficiently than the assumed maximal production of 1,200 PET/CT per system and year [26]. The real need is hard to judge, as it depends on the usefulness of pipeline tracers and clinical trials in progress. Obviously, more evidence-based knowledge is called for to convince potential users of the benefits of $\mathrm{PET} / \mathrm{CT}$.

The trend in Europe as a whole has been strikingly rapid despite many countries in which the number of systems and use of PET/CT are still far behind the average for Europe [13-15]. Commercial market analyses foresee a promising future for the European nuclear imaging equipment market, which was valued at $\$ 498.9 \mathrm{~m}$ in 2008 . It was forecast to grow by $16 \%$ annually for the next 7 years to reach $\$ 1.4$ billion by 2015, a growth that will "primarily be driven by increasing utilisation of SPECT/CT and PET/CT, the increase in the number of cancer patients across Europe, technological advances, and improvements in the quality of care" [27]. A forecast sponsored by the European Association of Nuclear Medicine on "The medical use of radiopharmaceuticals up to 2025 " points in the same direction [28]. Experts anticipate that multiple techniques like PET/ $\mathrm{CT}$ and even PET/MRI will play a central part in diagnostic imaging in the near future and that the use of PET/CT will increase significantly and that of SPECT/CT slightly, whereas other large scale techniques like CT, MRI, SPECT alone and ultrasound will decrease over the entire period from 2008 to 2025. Industrial respondents and interviewees that use these techniques indicate that this is currently the strongest development and that developments in multiple techniques seem to promote the progress of PET [28]. Although suggestive, these predictions might be taken with a grain of salt when we remember the impressive progress made with CT in recent years, although many wrote off this modality in the $1990 \mathrm{~s}$.

In our first 3 years, FDG was the dominating tracer and cancer by far the disease most commonly examined. However, according to a recent survey on multiple technique imaging in Europe, clinical PET or PET/CT was used also for neurology, infection/inflammation and cardiology purposes by $39 \%, 30 \%$ and $25 \%$ of responding members of the European Society of Radiology and by $60 \%, 54 \%$ and $40 \%$ of responding members of the European Association of Nuclear Medicine, respectively [29]. In addition, tracers other than FDG were applied by $5 \%-10 \%$ of radiological and by $6 \%-29 \%$ of nuclear medicine responders, suggesting that similar tendencies will emerge in new departments like ours. Our survey suggests that if available, PET/CT is going to be used.

In conclusion, without capacity limitations, the use of $\mathrm{PET} / \mathrm{CT}$ increased steeply and linearly during the first 3 years and changed diagnosis and/or staging and/or treatment plan in about one third of cases. These tendencies were in line with Danish and European trends, recent oncological database results from the US, forecasts by European specialist societies and marketing analyses-all of which foresee the increasing clinical use of functional at the expense of anatomical imaging.

Open Access This article is distributed under the terms of the Creative Commons Attribution Noncommercial License which permits any noncommercial use, distribution, and reproduction in any medium, provided the original author(s) and source are credited.

\section{References}

1. Centers for Medicare and Medicaid Services (2002-2009) NCD for Positron Emission Tomography (PET) Scans (220.6) [Medical Coverage Database on the Internet]. Centers for Medicare and Medicaid Services, Baltimore. Available via http://www.cms.hhs. gov $/ \mathrm{mcd} /$ viewncd.asp? $\mathrm{ncd}$ id $=220.6 \&$ ncd version $=4 \&$ basket $=$ ncd $\% 3 \mathrm{~A} 220 \% 2 \mathrm{E} 6 \% 3 \mathrm{~A} 4 \% 3$ APPositron+Emission+Tomography+\% 28PET\%29+Scans. Accessed 21 July 2010

2. Hillner BE, Liu D, Coleman RE, Shields AF et al (2007) The National Oncologic PET Registry (NOPR): design and analysis plan. J Nucl Med 48:1901-1098

3. Podoloff DA, Advani RH, Allred C et al (2007) NCCN task force report: positron emission tomography (PET)/computed tomography (CT) scanning in cancer. J Natl Compr Cancer Netw 5(Suppl 1):S1-S22

4. Boellaard R (2009) Standards for PET image acquisition and quantitative data analysis. J Nucl Med 50:11S-S20

5. Boellaard R, O'Doherty MJ, Weber WA et al (2010) FDG PET and PET/CT: EANM procedure guidelines for tumour PET imaging: version 1.0. Eur J Nucl Med Mol Imaging 37:181-200

6. Allen-Auerbach M, Weber WA (2009) Measuring response with FDG-PET: methodological aspects. Oncologist 14:369-377

7. Weber WA (2009) Assessing tumor response to therapy. J Nucl Med 50:1S-10S

8. Wahl RL, Jacene H, Kasamon Y, Lodge MA (2009) From RECIST to PERCIST: Evolving Considerations for PET response criteria in solid tumors. J Nucl Med 50:122S-150S

9. Långström B, Bergström M, Antoni G, Engler E (2001) Uppsala University PET Centre 1989-2001. Uppsala University PET Centre, Uppsala

10. About Turku PET Centre-History. Turku PET Centre, Turku. Available via http://pet.utu.fi/history.html. Accessed 21 July 2010

11. Rodell A (2003) On the trail of inner life. PET in Århus 19932003. Århus PET Center, Århus

12. Danish Institute of Radiation Protection (2009) [The use of radiopharmaceutical in nuclear medicine examinations and treatments in Denmark 2008]. Danish Institute of Radiation Protection, Danish National Board of Health, Copenhagen. Available via http:// www.sst.dk/pub1/Publ2009/SIS/Nuklear_medicin/Nuklearmedi cinsk_sammentaelling 2008.pdf. Accessed 21 July 2010

13. European Association of Nuclear Medicine (2006) Status of nuclear medicine in Europe-2006. EANM'06 statistics survey. EANM, Vienna

14. European Association of Nuclear Medicine (2007) Status of nuclear medicine in Europe-2007. EANM'07 statistics survey. EANM, Vienna 
15. European Association of Nuclear Medicine (2009) Status of nuclear medicine in Europe-2009. EANM'09 statistics survey. EANM, Vienna

16. World Health Organisation (2007) International Statistical Classification of Diseases and Related Health Problems 10th Revision. Version for 2007. World Heath Organisation and German Institute of Medical Documentation and Information. Available from. http://apps.who.int/classifications/apps/icd/icd10online/. Accessed 21 July 2010

17. Tucker R, Coel M, Ko J, Morris P, Druger G, McGuigan P (2001) Impact of fluorine-18 fluorodeoxyglucose positron emission tomography on patient management: first year's experience in a clinical center. J Clin Oncol 19:2504-2508

18. Gutte H, Højgaard L, Kjær A (2005) Early clinical experience and impact of 18F-FDG PET. Nucl Med Commun 16:989-994

19. Gopalan D, Griffiths D, Townsend C, Prvulovich E, Bomanji J, Costa DC, Ell PJ (2002) Fluorodeoxyglucose positron emission tomography in clinical oncology: the referrer's perspective. Nucl Med Commun 23:1041-1046

20. Hillner BE, Tunuguntla R, Fratkin M (2004) Clinical decision associated with positron emission tomography in prospective cohort of patients with suspected or known cancer at one United States center. J Clin Oncol 22:4147-4156

21. Lau WF, Binns DS, Ware RE, Ramdave S, Cachin F, Pitman AG, Hicks RJ (2005) Clinical experience with the first combined positron emission tomography/computed tomography scanner in Australia. Med J Aust 182:172-176

22. Hillner BE, Siegel BA, Liu D et al (2008) Impact of positron emission tomography/computed tomography and positron emission tomography (PET) alone on expected management of patients with cancer: initial results from the National Oncologic PET registry. J Clin Oncol 26:2155-2161
23. Hillner BE, Siegel BA, Shields AF et al (2009) The impact of positron emission tomography (PET) on expected management during cancer treatment: findings of the National Oncologic PET Registry. Cancer 115:410-418, Erratum in: Cancer 115:1133

24. Facey K, Bradbury I, Laking G, Payne E (2007) Overview of the clinical effectiveness of positron emission tomography imaging in selected cancers. Health Technol 11:iii-iv, xi-267

25. Långström B, Grahnen A, Honoré PH et al (2009) The risk of exaggerated risk aversion - a life and death struggle for molecular imaging. Eur J Nucl Med Mol Imaging 36:1693-1694

26. Danish National Board of Health (2006) PET (Positron emission tomography). Recommendations for the elaboration of PET and FDG production]. Danish National Board of Health, Copenhagen. Available via http://www.sst.dk/publ/Pub12006/PLAN/PET/ PET FDG.pdf. Accessed 21 July 2010

27. Market Research.com (2009) Europe nuclear imaging equipment: market analysis and opportunity assessment. Available via http:// www.researchandmarkets.com/reports/1195848. Accessed 21 July 2010

28. European Association of Nuclear Medicine (2008) Official EANM Position: The medical use of radiopharmaceuticals up to 2025. An exploration of the future medical use of radioisotopes. A report written and translated by Technopolis Group, commissioned by the Dutch Ministry of Housing, Spatial Planning and the Environment (VROM), and supported by the Dutch Society of Nuclear Medicine (NVNG) under the lead of Dr. J.F. Verzijlbergen. Available via https://www.eanm.org/news/ official eanm position.php?navId $=658$. Accessed 21 July 2010

29. Cuocolo A, Bretnach É (2010) Multimodality imaging in Europe: a survey by the European Association of Nuclear Medicine (EANM) and the European Society of Radiology (ESR). Eur J Nucl Med Mol Imaging 37:163-167 